\title{
THE RELATION OF CIRCULATING ANTIPNEUMOCOCCAL IMMUNE SUBSTANCES TO THE COURSE OF LOBAR PNEUMONIA
}

\section{ACQUIRED IMMUNE SUBSTANCES}

\author{
By O. H. ROBERTSON, JAMES B. GRAESER, LOWELL T. COGGESHALL, \\ AND M. AGNES HARRISON
}

(From the Department of Medicine and the Douglas Smith Foundation for Medical Research of the University of Chicago, Chicago)

(Received for publication March 12, 1934)

In an earlier study of those factors concerned in the mechanism of recovery from pneumococcus lobar pneumonia, we found that the patients' serum at the time of crisis or lysis acquired the property of promoting the destruction of the homologous pneumococcus when tested in vitro with rabbit serum-leukocyte mixtures (1). Our results agreed essentially with the findings of others on the occurrence of mouse-protective action in the serum of patients recovering from this disease and presumably have the same significance. However, in our series of cases, the pneumococcidalpromoting activity of the serum occurred more regularly and was more closely associated with the time of beginning recovery than was the reported occurrence of mouse protective properties. Further observations on our part have failed to reveal such a uniform chronological connection with the termination of the disease. Not infrequently, heat stable pneumococcidal-promoting activity of the serum was detected 2 to 3 days before crisis or in certain cases, not until after this event. Thus, while a direct causal association between detectable humoral immunity and recovery cannot be inferred, it seems likely, in view of the nature of the action of the circulatory antipneumococcal substances, that certain changes in the course of the disease indicating increased control on the part of the body over the infectious process may be ascribable to this effect. The present investigation, which comprises a considerably larger series of cases than did the earlier one, was undertaken with a view to inquiring more particularly into the relationship which the occurrence of these newly acquired immune bodies might bear to the spread of the pulmonary lesion and the localization of the infecting organism in the lung.

\section{METHODS}

The technique employed for the detection of the acquired pneumococcidal-promoting properties of the serum was the same as that described 
in former publications (1) (2). Briefly, dilutions of the test serum were added to constant amounts of rabbits serum and leukocytes which were then seeded with $10^{-6}$ of the standard pneumococcus suspension. This quantum contained 500 to 1,000 pairs of pneumococci and was uniform in each test. Serum samples from each patient heated to $56^{\circ} \mathrm{C}$. for $1 / 2$ hour were tested at one time with the homologous pneumococcus, or if the disease was caused by Type $I$, a highly virulent Type $I$ strain, $A_{5}$, was employed. The virulence of the pneumococcus isolated from each patient was tested in adult rabbits and mice and if found to be of low virulence for the former, the serum and leukocytes from rabbits weighing about 500 grams were used, since the blood of rabbits at this stage of growth possesses no demonstrable pneumococcidal activity even for pneumococci of very low virulence for full grown animals (3).

In addition, part of each serum sample from a number of cases was kept unheated and tested for natural immune properties as described in the preceding paper (4). Mouse protection tests were carried out in a few instances both with fresh and heated serum. The opsonic and agglutination activity of the serum was also determined in several cases.

Blood cultures and serial $\mathrm{x}$-rays were made on each case as described in Paper I (4).

\section{CLINICAL CASES}

Observations relating the appearance of acquired immune substances to the spread of the pulmonary lesion, blood invasion and outcome were carried out in thirty cases of pneumococcus lobar pneumonia. Twentyfour of these patients recovered.

The distribution of pneumococcus types among them was as follows: Type I, 1 case; Type II, 2 cases; Type IIa, 4 cases; Type III, 7 cases and Group IV, 13 cases. $^{1}$

A summary of the findings in this group is presented in Table I.

\section{Occurrence of immune substances}

An examination of the data shown in Table I reveals the fact that pneumococcidal-promoting properties appeared or increased in the blood serum of all the patients recovering from the disease and in only one of the six fatal cases. In three cases, Numbers 1,11 , and 20 , the heated diluted serum showed no pneumococcidal-promoting activity at any time while the fresh whole serum was found to possess this property to a well marked degree. All three serums showed mouse-protective action (see Table III). In two of these the immune properties were detected for the first time toward the end of the disease. In the other, demonstrable immunity had

1 The relatively small number of Types I and II in this series is due to the fact that patients with these two types were usually treated with serum and hence fall into the third part of the study. 
TABLE I

Relation of acquired immune substances to course of disease

\begin{tabular}{|c|c|c|c|c|c|c|c|}
\hline \multirow{3}{*}{ Case number } & \multirow{3}{*}{ Type } & \multicolumn{2}{|c|}{$\begin{array}{l}\text { Day of appearance of } \\
\text { pneumococcidal activity }\end{array}$} & \multirow{3}{*}{$\begin{array}{c}\text { Day of } \\
\text { beginning } \\
\text { recovery } \\
\text { or } \\
\text { death }\end{array}$} & \multirow{3}{*}{$\begin{array}{l}\text { Spread of } \\
\text { lesion after } \\
\text { appearance } \\
\text { of serum } \\
\text { immunity }\end{array}$} & \multirow{2}{*}{\multicolumn{2}{|c|}{$\begin{array}{l}\text { Blood invasion } \\
\text { in relation to } \\
\text { appearance of } \\
\text { serum immunity }\end{array}$}} \\
\hline & & \multirow{2}{*}{$\begin{array}{l}\text { Heated } \\
\text { diluted } \\
\text { serum }\end{array}$} & \multirow{2}{*}{$\begin{array}{l}\text { Fresh } \\
\text { whole } \\
\text { serum }\end{array}$} & & & & \\
\hline & & & & & & Before & After \\
\hline 1. (H. C.). & III & None & $4 \mathrm{th}^{*}$ & R 3d & 0 & + & 0 \\
\hline 2. (E. C.). & IV & 1st $(1: 20)$ & 1st & R 2d & $t^{\Delta}$ & - & - \\
\hline 3. (G. B.). . & IV & 5 th $(1: 80)$ & - & R 4th & 0 & $\mathbf{0}$ & $\mathbf{0}$ \\
\hline 4. (R. M. E.) & II $a$ & 5 th $(1: 20)$ & $3 d^{* *}$ & R 6th & $t^{\Delta}$ & $\mathbf{0}$ & $\mathbf{0}$ \\
\hline 5. (K. H.)... & III & 4th $(1: 40)$ & 4th & R 6th & $t^{\Delta}$ & 0 & 0 \\
\hline 6. (L. G.). & III & 5 th $(1: 80)$ & - & R 5th & 0 & $\mathbf{0}$ & 0 \\
\hline 7. (R. E.). & II & 1st $(1: 320)$ & 1st & R 1st & - & $\mathbf{0}$ & - \\
\hline 8. (R. K.). & IV & 15th $(1: 40)$ & - & R 18th & + & 0 & $\mathbf{0}$ \\
\hline 9. (M. M.). & II & 7 th $(1: 20)$ & 7 th & R 9th & 0 & 0 & 0 \\
\hline 10. (W. S.). & IV & 6th $(1: 640)$ & $5 \mathrm{th}^{*}$ & R 8th & 0 & + & 0 \\
\hline 11. (N. S.)... & II & None & 10 th $^{*}$ & R 9th & $\mathbf{0}$ & 0 & 0 \\
\hline 12. (A. R.). & IV & 10 th $(1: 80) \oplus$ & - & R 5th & 0 & + & 0 \\
\hline 13. (A. Z.).. & III & 6th $(1: 160)$ & $6 \mathrm{th}^{*}$ & R 6th & 0 & 0 & 0 \\
\hline 14. (L. P.).. & II $a$ & $3 d(1: 40)$ & $3 d$ & R 4th & 0 & 0 & $\mathbf{0}$ \\
\hline 15. (M. K.). & II $a$ & 6th $(1: 320)$ & - & R 6th & - & $\mathbf{0}$ & $\mathbf{0}$ \\
\hline 16. (R. B.).. & IV & 7 th $(1: 80)$ & 6th & R 6th & $\mathbf{0}$ & $\mathbf{0}$ & 0 \\
\hline 17. (B. G.). & II $a$ & 5th $(1: 40)$ & 5 th & R 5th & 0 & 0 & 0 \\
\hline 18. (Y. B.). & II $a$ & 8th $(1: 40)$ & 7 th & R 6th & - & + & $\mathbf{0}$ \\
\hline 19. (M. K.). & IV & 8 th $(1: 640)$ & 5 th & R 5th & 0 & 0 & 0 \\
\hline 20. (F. V.).. & IV & None & 8th & R 9th & 0 & + & 0 \\
\hline 21. (A. L.).. & I & 5 th $(1: 40)$ & $3 d$ & R 6th & $+\Delta$ & 0 & 0 \\
\hline 22. (F. T.) .. & IV & 9th $(1: 20)$ & - & R 8th & 0 & - & - \\
\hline 23. (L. M. B.). & II $a$ & 9 th $(1: 80)$ & 8th & R 8th & $\mathbf{0}$ & + & $\mathbf{0}$ \\
\hline 24. (R. R.) . . & IV & 6th $(1: 320)$ & - & R 6th 8 & 0 & 0 & 0 \\
\hline 25. (B. B.). & III & 9th $(1: 40)$ & - & D 11 th & $+\Delta$ & 0 & 0 \\
\hline 26. (H. B.). & IV & None & - & D 12th & - & + & \\
\hline 27. (B. D.). & IV & None & - & D 8th & - & + & \\
\hline 28. (C. H.). & III & None & None & D 10th & & + & \\
\hline 29. (E. K.). & IV & None & - & D 10th & & + & \\
\hline 30. (S. R.).. & III & None & - & D 7th & & + & \\
\hline
\end{tabular}

$+=$ present.

$0=$ absent.

$-=$ no observations made.

$\mathrm{R}=$ recovered.

$\mathrm{D}=$ died.

The figures in column $3(1: 20)$, (1:40), etc. represent the highest dilution of the patients serum which, added to rabbits serum and leukocyte mixtures, caused death of all the pneumococci contained in $10^{-6}$ of the standard pneumococcus suspension i.e. 500 to 1,000 micro-organisms.

* These patients showed an increase in the pneumococcidal-promoting activity of the whole serum which had been present to a varying degree from the beginning of the observations.

** Patient was given Type II concentrated antibody solution.

$\S$ Died 5 days later of nephritic uremia. Lungs at autopsy showed well advanced resolution of the lobes previously consolidated.

$\Delta=$ No new lobe involvement.

$\oplus=$ Test on serum on 7 th day negative. No further test until the 10th day. 
been constantly present, but showed a definite terminal increase. Whether the antipneumococcal activity found in the blood of these three patients represents the acquisition of new immune properties or only the recurrence of natural immune bodies which had diminished or disappeared during the active stage of the disease will be discussed later. It makes no essential difference in the chief inferences to be drawn from this study whether they are classified in one group or the other.

\section{Relation of appearance of serum immunity to time of recovery}

A tabulation of the recovering patients with respect to the day on which immune substances first appeared in the blood serum (Table II) shows no close relationship of this phenomenon to the onset of recovery. Less

TABLE II

Relation of appearance of serum immunity to recovery *

\begin{tabular}{|c|c|c|c|c|c|c|c|}
\hline \multirow{3}{*}{ Kind of pneumococcidal test } & \multicolumn{7}{|c|}{$\begin{array}{l}\text { Appearance of pneumococcidal-promoting action in relation } \\
\text { to beginning of recovery }\end{array}$} \\
\hline & \multicolumn{3}{|c|}{ Before } & \multirow{2}{*}{$\begin{array}{c}\text { Day } \\
\text { of }\end{array}$} & \multicolumn{3}{|c|}{ After } \\
\hline & 3 days & 2 days & 1 day & & 1 day & 2 days & 3 days \\
\hline $\begin{array}{l}\text { Fresh whole serum } \\
\text { Number of cases } \ldots \ldots \ldots \ldots \ldots \\
\text { Heated diluted serum } \\
\text { Number of cases } \ldots \ldots \ldots \ldots \ldots\end{array}$ & 3 & 2 & $\begin{array}{l}2 \\
4\end{array}$ & $\begin{array}{l}4 \\
6\end{array}$ & 2 & 1 & 1 \\
\hline
\end{tabular}

* This data is taken from Table I. Tests with the fresh whole serum were not performed on all the cases tested for acquired immune serum substances.

than half the cases showed the first appearance of serum immunity on the day of beginning recovery. The immune substances occurred more often before recovery than subsequent to it and in several instances as early as three days beforehand.

It is probably significant that in the two patients which showed an abortive type of pneumonia (Cases 2 and 7, Table I) acquired immune properties of the serum were demonstrable on the first day of the disease. Patient R. E., Number 7, exhibited all the classical symptoms of lobar pneumonia which lasted less than 18 hours. No evidence of consolidation was detected either by $\mathrm{x}$-ray or physical signs, but a virulent Type II pneumococcus was isolated from the sputum. The pneumococcidal-promoting activity of the serum secured within a few hours after the onset of the disease was greater than that shown by the majority of patients at the time of recovery. However, the early presence of acquired immune substance is not always followed by prompt recovery as was found in Case 20, F. P. R. (Paper III, Table I) whose serum showed on the second day of the dis- 
ease a pneumococcidal promoting titer of the same degree as that of Case 2 (E. C.) above mentioned, but which had disappeared by the fourth day. Recovery did not occur until the seventh day despite the restoration of immune properties in the blood by the injection of antipneumococcus serum.

\section{Spread of the pulmonary lesion}

While, in the majority of instances, there was no increase in the extent of the pulmonary lesion after the appearance of acquired immune bodies, a further spread of the process did occur in six cases despite the presence of demonstrable humoral immunity. In several patients the pulmonary lesion continued to enlarge for two to three days following the initial finding of humoral immunity, but in only one case, Number 8 , was there detectable spread to a new lobe.

On the other hand the lesion remained stationary in its extent in several patients whose blood lacked demonstrable immune properties. (See Cases 19 and 20, Tables I and II, Paper I.)

Case 25, B. B., Chart I, the only fatal one showing the presence of acquired immune substances, deserves special comment. In this patient a progressive spread of the pneumonic process occurred throughout the period of observation from the fourth day of the disease until death on the eleventh day. On the ninth day the serum showed pneumococcidal-promoting titer of $1: 40$. This increased to $1: 80$ and persisted until the time of death. By the ninth day almost one half of the lung area was involved and by the eleventh day this had increased to three quarters. It seems likely in this instance that the accompanying marked anoxemia was an important factor in the exitus, since at autopsy much of the involved lung tissue was found to be in a state of resolution. No complications were discovered.

\section{Bacteremia}

In six of the patients (Table I) recovering from the disease, pneumococci were isolated from the blood at some time during its course. In all of these cases the blood cultures became negative either before or coincident with the acquisition of humoral immune substances. On the other hand there were two instances, Cases 18 (Chart II) and 20 (Table II, Paper I) in which bacteremia disappeared in the absence of detectable humoral immunity. It may be significant that the only patient going on to a fatal termination without demonstrable bacteremia, showed the presence of immune properties in his blood for several days before death.

\section{Comparison of pneumococcidal-promoting activity of fresh whole serum and heated diluted serum}

(Natural and acquired immune substances)

The particular composition of the pneumococcidal test employed in this section of the study was designed to distinguish acquired from natural im- 
mune bodies. It was early discovered that dilution of fresh serum to $1: 10$ was often not sufficient to abolish its pneumococcidal-promoting action and in order to bring about complete destruction of the pneumococci, the presence of approximately this concentration of fresh serum was essential.

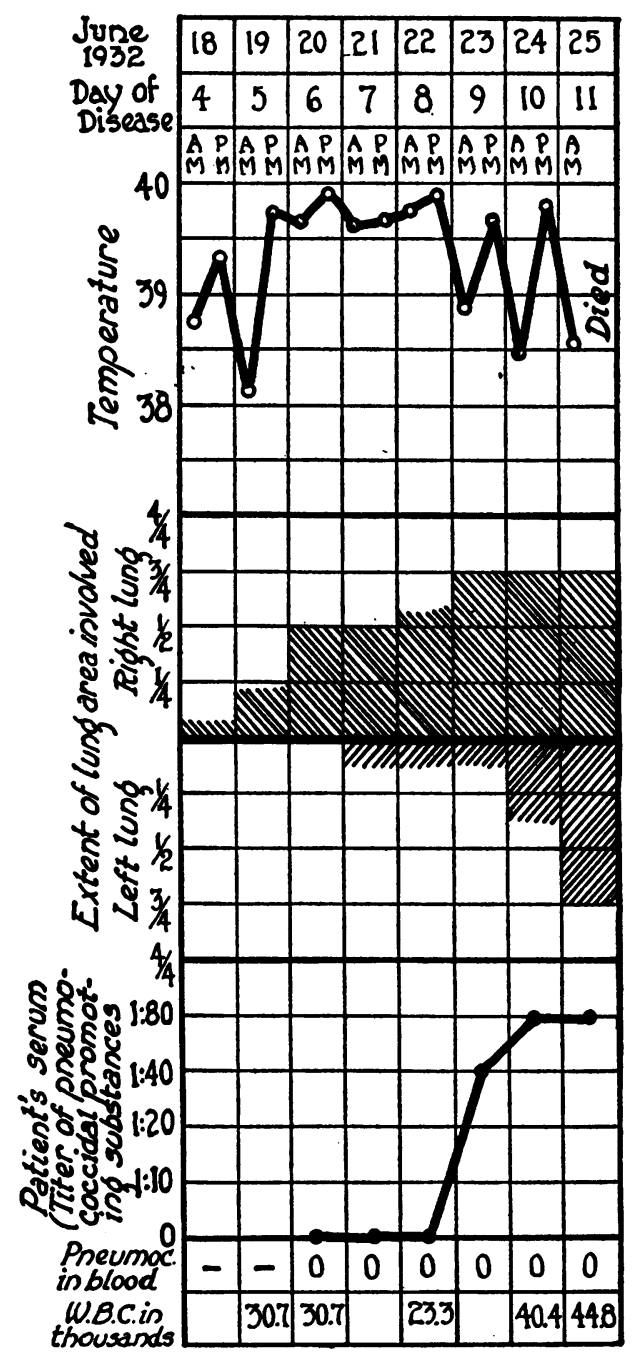

Chart I. Case Number 25 (B. B.). Lobar Pneumonia, Pneumococcus Type III Isolated from Sputum and the Lung at Autopsy

Thus, a human serum-leukocyte system could not be used for the detection of acquired immune substances unless these were present in high concentration. The difficulty was solved by the substitution of rabbits' serum and leukocytes and by inactivation of the human serum. When diluted 
1: 10 the inactivated normal human serum was without pneumococcidalpromoting action and at the same time produced no deleterious effect on the leukocytes. Concentrations of serum greater than 1:10 at times appeared to interfere with the normal functioning of the rabbit's leukocytes, hence this amount of serum was the maximum used in the tests, and to this extent the sensitivity of the test for low concentrations of immune substances is limited. In order to compare these two reactions a series of cases, in

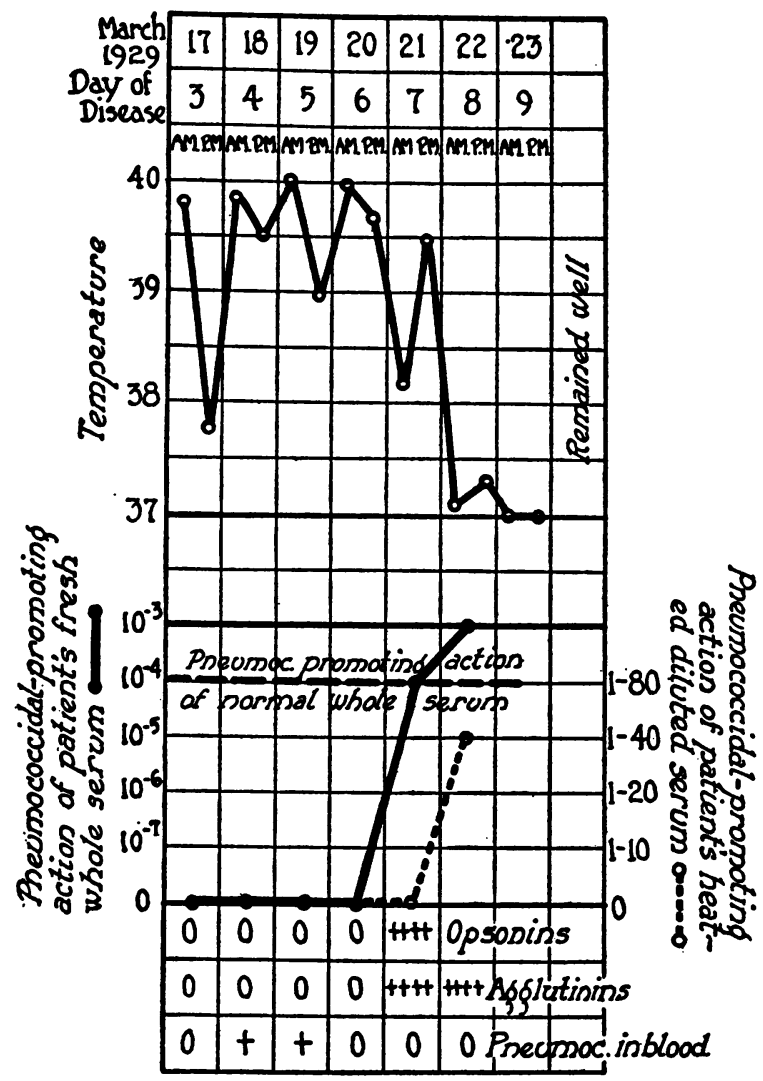

Chart II. Case Number 18 (Y. B.). Lobar Pneumonia; Pneumococcus Type II Atypical Isolated from Blood

which both tests were performed on the same sample of serum, are listed in Table III together with paralleled tests for mouse protection. It will be noted, first of all, that there is little parallelism quantitatively between the results of the two pneumococcidal tests. Some differences might be expected, since in the experiments with whole serum the numbers of pneumococci are varied and the amount of human serum held constant, while in the tests with heated serum the number of microorganisms was kept uniform 
TABLE III

Comparison of pneumococcidal tests with each other and with mouse protection *

\begin{tabular}{|c|c|c|c|c|c|}
\hline \multirow{2}{*}{$\begin{array}{c}\text { Case } \\
\text { number }\end{array}$} & \multirow{2}{*}{$\begin{array}{l}\text { Day of } \\
\text { disease }\end{array}$} & \multicolumn{2}{|c|}{ Pneumococcidal tests } & \multirow{2}{*}{$\begin{array}{c}\text { Mouse } \\
\text { protection }\end{array}$} & \multirow{2}{*}{$\begin{array}{c}\text { Day } \\
\text { of } \\
\text { beginning } \\
\text { recovery }\end{array}$} \\
\hline & & $\begin{array}{l}\text { Heated } \\
\text { diluted } \\
\text { serum }\end{array}$ & $\begin{array}{l}\text { Fresh } \\
\text { whole } \\
\text { serum }\end{array}$ & & \\
\hline 1. (H. C.)... & $\begin{array}{l}2 \mathrm{~d} \\
3 \mathrm{~d} \\
4 \mathrm{th}\end{array}$ & $\begin{array}{l}\mathbf{0} \\
\mathbf{0} \\
\mathbf{0}\end{array}$ & $\begin{array}{l}10^{-7} \\
10^{-6} \\
10^{-5}\end{array}$ & $\begin{array}{c}0 \\
10^{-4} \\
10^{-5} \\
\text { (Inact. ser.) }\end{array}$ & 3d \\
\hline 11. (N. S.) ... & $\begin{array}{l}\text { 2d } \\
4 \text { th } \\
6 \text { th } \\
8 \text { th } \\
10 \text { th }\end{array}$ & $\begin{array}{l}\mathbf{0} \\
\mathbf{0} \\
\mathbf{0} \\
\mathbf{0} \\
\mathbf{0}\end{array}$ & $\begin{array}{l}10^{-4} \\
10^{-3} \\
10^{-4} \\
10^{-6} \\
10^{-4}\end{array}$ & $\begin{array}{c}10^{-6} \\
10^{-7} \\
10^{-6} \\
10^{-6} \\
10^{-7} \\
\text { (Fresh ser.) }\end{array}$ & 9th \\
\hline 20. (F. V.) ..... & $\begin{array}{l}\text { 4th } \\
\text { 6th } \\
\text { 7th } \\
\text { 8th } \\
\text { 9th } \\
\text { 10th } \\
\text { 11th }\end{array}$ & $\begin{array}{l}\mathbf{0} \\
\mathbf{0} \\
\mathbf{0} \\
\mathbf{0}\end{array}$ & $\begin{array}{c}0 \\
10^{-7} \\
0 \\
10^{-4} \\
10^{-3} \\
10^{-3} \\
10^{-3}\end{array}$ & $\begin{array}{c}0 \\
10^{-7} \\
10^{-5} \\
10^{-6} \\
10^{-6} \\
10^{-5} \\
\text { (Inact. ser.) }\end{array}$ & 9th \\
\hline 13. (A. Z.)... & $\begin{array}{l}3 d \\
4 \text { th } \\
5 \text { th } \\
6 \text { th }\end{array}$ & $\begin{array}{c}0 \\
0 \\
0 \\
1: 160\end{array}$ & $\begin{array}{l}10^{-6} \\
10^{-7} \\
10^{-6} \\
10^{-5}\end{array}$ & $\begin{array}{c}0 \\
0 \\
0 \\
10^{-7} \\
\text { (Fresh ser.) }\end{array}$ & 6th \\
\hline 16. (R. B.).... & $\begin{array}{l}5 \text { th } \\
6 \text { th } \\
7 \text { th }\end{array}$ & $\begin{array}{c}0 \\
0 \\
1: 80\end{array}$ & $\begin{array}{c}0 \\
10^{-5} \\
10^{-4}\end{array}$ & $\begin{array}{l}- \\
-\end{array}$ & 6th \\
\hline 10. (W. S.)..... & $\begin{array}{l}\text { 4th } \\
\text { 5th } \\
\text { 6th } \\
\text { 7th } \\
\text { 8th }\end{array}$ & $\begin{array}{c}0 \\
0 \\
1: 640 \\
1: 1280 \\
1: 640\end{array}$ & $\begin{array}{l}10^{-5} \\
10^{-4} \\
10^{-4} \\
10^{-4} \\
10^{-4}\end{array}$ & $\begin{array}{l}- \\
\bar{z} \\
\overline{-}\end{array}$ & 8th \\
\hline
\end{tabular}

$0=$ no activity.

- = not done.

* The figures $10^{-3}, 10^{-4}$, etc. represent amounts of the standard pneumococcus suspension ( 1 billion micro-organisms per cc.) killed by the serum and leukocyte mixtures and under the heading "Mouse protection" they indicate the largest amount of injected pneumococcus suspension against which $0.2 \mathrm{cc}$. of the serum protected. $10^{-7}=$ approximately 100 pneumococci, $10^{-6}, 1000$, etc. 
TABLE III (continued)

\begin{tabular}{|c|c|c|c|c|c|}
\hline \multirow{2}{*}{$\begin{array}{c}\text { Case } \\
\text { number }\end{array}$} & \multirow{2}{*}{$\begin{array}{l}\text { Day of } \\
\text { disease }\end{array}$} & \multicolumn{2}{|c|}{ Pneumococcidal tests } & \multirow{2}{*}{$\begin{array}{c}\text { Mouse } \\
\text { protection }\end{array}$} & \multirow{2}{*}{$\begin{array}{c}\text { Day } \\
\text { of } \\
\text { begining } \\
\text { recovery }\end{array}$} \\
\hline & & $\begin{array}{l}\text { Heated } \\
\text { diluted } \\
\text { serum }\end{array}$ & $\begin{array}{l}\text { Fresh } \\
\text { whole } \\
\text { serum }\end{array}$ & & \\
\hline 21. (A. L.) $\ldots \ldots \ldots \ldots \ldots$ & $\begin{array}{l}\text { 1st } \\
2 d \\
3 d \\
4 \text { th } \\
5 \text { th } \\
6 \text { th }\end{array}$ & $\begin{array}{rl} & 0 \\
0 \\
0 \\
0 \\
1: \\
1: & 40 \\
1 & 640\end{array}$ & $\begin{array}{c}0 \\
0 \\
10^{-5} \\
10^{-4} \\
10^{-5} \\
10^{-3}\end{array}$ & $\begin{array}{l}- \\
\overline{-} \\
- \\
-\end{array}$ & 6th \\
\hline 15. (B. G.) $\ldots \ldots \ldots \ldots \ldots$ & $\begin{array}{l}3 d \\
4 \text { th } \\
5 \text { th } \\
6 \text { th }\end{array}$ & $\begin{aligned} & 0 \\
& 0 \\
1 & : 40 \\
1 & : 320\end{aligned}$ & $\begin{array}{c}0 \\
0 \\
10^{-6} \\
10^{-4}\end{array}$ & $\begin{array}{l}- \\
\bar{z}\end{array}$ & 5 th \\
\hline 14. (F.) (see Paper I)....... & $\begin{array}{l}3 \mathrm{~d} \\
5 \text { th } \\
7 \text { th }\end{array}$ & $\begin{array}{l}- \\
-\end{array}$ & $\begin{array}{l}10^{-5} \\
10^{-5} \\
10^{-4}\end{array}$ & $\begin{array}{c}10^{-5} \\
10^{-7} \\
10^{-7} \\
\text { (Inact. ser.) }\end{array}$ & 7 th \\
\hline 27. (H. F. V. L.) (see Paper I) & $\begin{array}{l}\text { 5th } \\
\text { 6th } \\
\text { 7th }\end{array}$ & $\begin{array}{l}- \\
-\end{array}$ & $\begin{array}{c}0 \\
10^{-5} \\
10^{-5}\end{array}$ & $\begin{array}{c}0 \\
0 \\
10^{-7} \\
\text { (Fresh ser.) }\end{array}$ & 7th \\
\hline
\end{tabular}

with varying dilutions of the serum. However, the variation in results observed in Case 10, for example, in which the effective concentration of heated serum changed from 0 to $1: 640$ within twenty-four hours, while the numbers of pneumococci killed by the fresh whole serum remained the same on these two days, cannot be explained on the basis of our knowledge concerning the mechanism by which the pneumococci are killed by the serum and leukocytes. ${ }^{2}$ The question of chief importance for the present consideration is that of the significance of the appearance of pneumococcidalpromoting action of the whole serum in patients whose blood, in the earlier part of the disease, has lacked this property. It was hoped that mouse protection tests would be of assistance, and the results of such tests do provide data of value since it will be observed that the pneumococcidal and mouseprotection activity of whole serum are of about equal sensitivity, the former being perhaps a little the more delicate of the two even when fresh serum is employed in both tests as in Cases 13 and 27.3 In Case 20, both pneumo-

${ }^{2}$ It is possible that this phenomenon may be of the same nature as that observed in mouse protection experiments with immune serum-namely that when the infecting dose of microorganisms reaches a certain maximum, no amount of immune serum, however large, will protect the animal.

${ }^{3}$ Sutliff and Rhoades (5) detected not infrequently whole blood pneumococcidal activity in the absence of mouse protective action of the serum. 
coccidal tests and mouse protection tests with fresh whole serum showed the appearance of serum immunity at about the same time while the heated diluted serum was without affect and remained so. An analogous result was evident in Case 1 in which there occurred a well marked increase of the pneumococcidal-promoting activity of the whole serum accompanied by the appearance of mouse-protection activity, while no action of the heated diluted serum was demonstrable.

Tests for opsonic action of the serum were informative. Case 18 (see Chart II) showed no serum opsonic activity until the seventh day of the disease which was the first day of appearance of pneumococcidal action of whole serum. The degree of opsonic action was much greater than that observed with normal serum. Activity of the heated diluted serum was not evident until the eighth day. The serum of several other cases showed increases in opsonic and agglutinative activity at about the time of recovery, but these reactions did not parallel strictly the changing intensity of the pneumococcidal and mouse protective properties of the serum.

In conclusion it may be said that in our experience the demonstration of pneumococcidal action in the mixture of heated human serum with rabbit serum and leukocytes indicates the presence of so-called acquired humoral immunity. The appearance late in the disease of pneumococcus-killing power in the mixtures of fresh whole human serum and leukocytes is probably indicative of the same reaction since such serum has been found to contain mouse-protection activity which was not present previously. However, in an instance such as presented by Case 11 (N. S.) where the blood showed pneumococcus-killing properties throughout the course of the disease and the mouse-protection action of the serum was minimal and not demonstrable with inactivated serum, one cannot draw any inferences concerning the nature of the increase in humoral immunity at the end of the disease. Finally, we wish to point out that this attempt to distinguish between natural and immune substances does not imply a conception of two separate immunological entities. There is considerable experimental evidence to indicate that they are one and the same, the difference being quantitative and not qualitative.4

\section{DISCUSSION}

That the appearance of circulating type specific antibodies may be regarded as an indication of the body's successful reaction against pneumococcus infection seems clear from both the clinical and experimental evidence at hand. Accumulating data also show that this manifestation of immunity to pneumococci is found with great regularity in patients recovering from lobar pneumonia (7) (8) (9). But it may not become ap-

4 The whole matter of the relationship between natural and acquired opsonins has been ably reviewed by Zinsser (6). 
parent until days or even weeks after recovery. In a recent communication Lord and Persons (8) report two instances of repeated tests on the serum of two patients with pneumonia who failed to show mouse-protective action until the 20th and 25th days respectively, after the termination of disease. Moreover, the development of humoral immunity does not always insure recovery. There are records of a few cases which have progressed to a fatal termination despite the presence of immune substances in their serum. The course of the disease in most of these instances has been prolonged far beyond its usual limits. Lord and Persons report two such cases. One was found at autopsy to have a pneumococcus endocarditis, the other dying at the end of 23 days had an infected chest fluid. Trask and his associates (9) observed one case which showed slight mouse-protective action in the serum on the 11th day and died on the 17th day with a staphylococcus abscess in the lung. Clough reports one case dying with complications (10). Our case described above died on the 11th day with extensive consolidation of the lungs, but without complications. ${ }^{5}$

Perhaps of more significance than the presence of humoral immune substances is their absence from the serum in many instances until after the time of recovery, because it suggests that the body possesses other and highly effective means for restraining the spread of the pneumonic process, localizing the invading microorganism within the lesion and eventually terminating the infection. Our findings make it seem doubtful whether the presence of pneumococcidal-promoting or mouse-protective substances have anything to do with the control of the spread of the lesion within the lung, since extension of the pulmonary process was observed to occur in a number of instances after the appearance of humoral immunity (see Table I) and, on the contrary, the lesion remained static for days in patients whose serum was without detectable immune properties either natural or acquired. With respect to bacteremia, however, there is some positive evidence that acquired immune substances exert a controlling influence. In all of our cases with bacteremia, the appearance of serum immunity marked its termination, and in the one case dying after the acquisition of this property, the blood remained sterile. On the other hand, Lord and Persons report two cases in which bacteremia persisted in the presence of acquired serum immunity. Sutliff and Rhoades also observed one case which probably falls into this category. Our cases, in which negative blood cultures were obtained throughout the course of the disease without demonstrable antipneumococcal activity in the serum, imply the existence of other factors operating to prevent the liberation of pneumococci into the blood stream.

${ }^{5}$ In a study which has just been published (21), Winkler and Finland found mouse protective action late in the disease in the serum of a number of patients with Type III and higher type (newly classified) pneumonias. Also Finland and Winkler failed to find immune substances in a considerable percentage of Type III and Type VIII pneumonias recovering from the disease (22). 
The objection that our methods may not be sufficiently sensitive to detect small concentrations of these immune bodies in the blood cannot be answered directly, but our finding (described in Paper I) of bacteremia in the presence of minimal concentrations of natural immune substances is pertinent in this connection.

The question of the state of functional activity of the phagocytic cells of the body is of importance especially in those instances where the humoral immune substances apparently fail to exert the effects which might logically be expected from their presence. Tests on the phagocytic activity of the circulating leukocytes have failed to disclose any significant disturbance of this function (11) (12) (13). We have substituted leukocytes obtained from patients in different stages of lobar pneumonia, for normal leukocytes in pneumococcidal tests and found them to be equally effective in bringing about the destruction of virulent pneumococci. While these findings do not preclude the occurrence of a diminished antipneumococcal activity of the leukocytes under particular conditions, they do suggest that this function is a relatively stable one. Concerning the activities of the fixed tissue cells we have no information.

Certain findings in studies on the mechanism of recovery from experimental pneumococcus infection are of much interest here. Cecil and Blake (14) failed to detect the presence of mouse protection activity in the serum of monkeys recovering from experimental lobar pneumonia, although these monkeys had acquired well marked immunity as shown by their resistance to re-infection. Cecil and Steffen (15) found that monkeys could be rendered resistant to pneumococcus infection by means of vaccination with killed pneumococci, but they were unable to detect mouse-protective activity in the serum of such immune animals. In a study of repeated attacks of experimental lobar pneumonia in dogs (16) we found marked variations in different animals with respect to the occurrence of detectable humoral immunity. Some dogs showed considerable concentrations of specific immune substances following an attack of the disease; others showed none. Yet these latter animals when tested by re-infection were fully as resistant as the dogs exhibiting acquired humoral immunity. On the other hand, cats recovering from experimental pneumococcus infection regularly developed a relatively high degree of antipneumococcal activity in their blood (17). That the antipneumococcal response of human beings resembles more nearly that of the cat than the other animal species, is born out by clinical findings and the observations of Barach (18) in vaccination of human subjects with pneumococcus vaccine. A high percentage of such vaccinated individuals, patients with lobar pneumonia as well as others without infection of the respiratory tract, showed the appearance of mouse protective properties in the serum within four to six days.

Do the variations in the elaboration of antipneumococcal substances observed in the different animal species or in different individuals of a single 
species represent differing responses of the same reaction, or is there another mechanism common to all these species upon which the body depends principally for its recovery from localized pneumococcus infection? In our earlier study of this subject (1), we assigned more importance to the part played by humoral immune properties in recovery from lobar pneumonia than these later and more extensive observations would warrant. Further evidence suggesting that circulating immune substances may, under certain conditions, play a subordinate rôle in this process, has been supplied by several cases of pneumonia in whom we have observed clearing of the pneumonic lesion in one area while extension was taking place elsewhere in the lung. An instance of this kind, pictured in Chart II of Paper I (4), showed progressive resolution of the initially consolidated right lower lobe during the period that spread to the right upper lobe was occurring. ${ }^{6}$ A second patient has recently come under our observation in whom early and rapid disappearance of the first consolidated area of the right lower lobe (the lateral inferior segment) occurred while involvement of the remainder of the lobe was taking place. Case 4, Table I, showed this phenomenon on the day preceding crisis. In the study of experimental lobar pneumonia in the dog (20) we have noted frequently clearing of the lesion and spread of the lesion occurring simultaneously in different parts of the lung field. Additional evidence of what might be termed local or regional recovery is provided by our not uncommon finding at autopsy of beginning resolution in certain areas of the consolidated lung in patients without detectable circulatory immune substances. Microscopic examination of such regions shows pneumococci to be few or absent, while in neighboring areas which are still intensely consolidated, microorganisms are usually abundant. Although any proposed explanation of such changes is at present entirely speculative, it would seem to us that the supposition of acquired antipneumococcal immunity by the local tissue cells is not inconsistent with the phenomena observed. It is also conceivable that a widespread specific reaction of the pulmonary fixed tissue cells may play an important part in the mechanism of recovery from lobar pneumonia. This conception would not exclude the participation of immune substances in the process.

\section{SUMMARY}

Observations relating the appearance of acquired immune substances to the spread of the disease, blood invasion and recovery were carried out in thirty cases of pneumococcus lobar pneumonia. Acquired antipneumococcal immune properties were detected in the serum in all of the patients recovering and in only one of the six fatal cases. However, the appearance of this immune reaction was not closely related to the onset of recovery. In many instances it was found two or three days beforehand or not until

${ }^{6} \mathrm{X}$-rays of this patient's lungs are presented in another communication (19). 
a day or so afterwards. While in the majority of the patients there was no increase in the extent of the lesion, as determined by serial x-rays, after the appearance of the newly acquired immune bodies, a further spread of the process did occur in six cases. Bacteremia ceased either before or coincident with the occurrence of demonstrable humoral immunity. However, the blood remained sterile throughout the course of the disease in several cases, showing neither natural nor acquired immunity. Furthermore, the pulmonary lesion remained static for a number of days in some cases showing a similar lack of antipneumococcal activity in their blood serum.

These findings suggest that either the body brings into play more than one mechanism for restraining the spread of the pneumonic process, localizing the invading microorganism within the lesion and eventually terminating the infection, or that the elaboration of humoral immune substances represents only one phase of a specific reaction against the pneumococcus.

\section{BIBLIOGRAPHY}

1. Sia, R. H. P., Robertson, O. H., and Woo, S. T., A study of the mechanism of recovery from lobar pneumonia. J. Exper. Med., 1928, 48, 513.

2. Robertson, O. H., Sia, R. H. P., Studies on pneumococcus growth inhibition. III. The influence of specific antipneumococcus serum on the growthinhibitory and bactericidal action of normal serum-leukocyte mixtures. J. Exper. Med., 1924, 40, 467.

3. Woo, S. T., Studies on pneumococcus growth inhibition. V. The relation of virulence to the pneumococcidal activity of normal rabbit serum leukocyte mixtures. J. Exper. Med., 1926, 43, 623.

4. Robertson, O. H., Graeser, J. B., Coggeshall, L. T., and Harrison, M. A., The relation of circulating antipneumococcal immune substances to the course of lobar pneumonia. I. Natural immune substances. J. Clin. Invest., 1934, 13, 621.

5. Sutliff, W. D., and Rhoades, D. R., The pneumococcidal power of whole blood. II. Estimations in lobar pneumonia. J. Clin. Invest., 1930, 9, 55.

6. Zinsser, H., Resistance to Infectious Diseases. MacMillan and Co., Philadelphia, 1931, 4th ed., p. 333.

7. Baldwin, H. S., and Cecil, R. L., The rationale of specific therapy in pneumococcus pneumonia. J. A. M. A., 1926, 87, 1709.

8. Lord, F. T., and Persons, E. L., Certain aspects of mouse protection tests for antibody in pneumococcus pneumonia. J. Exper. Med., 1931, 53, 151.

9. Trask, J. D., O'Donovan, C., Jr., Moore, D. M., and Beebe, A. R., Studies on pneumonia in children. I. Mortality, blood cultures and humoral antibodies in pneumococcus pneumonia. J. Clin. Invest., 1930, 8, 623.

10. Clough, P. W., Phagocytosis and agglutination in the serum in acute lobar pneumonia; The specificity of these reactions and the regularity of their occurrence. Bull. Johns Hopkins Hosp., 1919, 30, 167.

11. Tunnicliff, R., On variations in phagocytic and coccidal power of the blood in pneumonia and scarlet fever. J. Infect. Dis., 1911, 8, 302.

12. Rosenow, E. C., The rôle of phagocytosis in the pneumococcidal action of pneumonic blood. J. Infect. Dis., 1906, 3, 683. 
13. Eggers, H. E., On the antipneumococcal powers of the blood in pneumonia. J. Infect. Dis., 1912, 10, 48.

14. Cecil, R. L., and Blake, F. G., Studies on experimental pneumonia. VI. Active immunity following experimental pneumococcus pneumonia in monkeys. J. Exper. Med., 1920, 31, 685.

15. Cecil, R. L., and Steffen, G. I., Studies in pneumococcus immunity. II. Active immunization of monkeys against pneumococcus Types II, III and IV pneumonia with the homologous pneumococcus vaccine. J. Exper. Med., 1923, 38, 149.

16. Coggeshall, L. T., and Robertson, O. H., A study of repeated attacks of experimental pneumococcus lobar pneumonia in dogs. (To be published.)

17. Robertson, O. H., Woo, S. T., Cheer, S. N., and King, L. P., A study of the mechanism of recovery from experimental pneumococcus infection. J. Exper. Med., 1928, 47, 317.

18. Barach, A. L., Factors involved in the production of immunity with pneumococcus vaccine. II. Induction of active immunity during the course of lobar pneumonia. J. Exper. Med., 1931, 53, 567.

19. Graeser, J. B., Wu, C., and Robertson, O. H., Physical signs and roentgenographic findings in lobar pneumonia in adults. Arch. Int. Med., 1934, 53, 249.

20. Terrell, E. E., Robertson, O. H., and Coggeshall, L. T., Experimental pneumococcus lobar pneumonia in the dog. I. Method of production and course of the disease. J. Clin. Invest., 1933, 12, 393.

21. Winkler, A. W., and Finland, M., Antibody response to infections with the newly classified types of pneumococci (Cooper). J. Clin. Invest., 1934, 13, 109.

22. Finland, M., and Winkler, A. W., Antibody response to infections with Type III and the related Type VIII pneumococcus. J. Clin. Invest., 1934, 13, 79. 